\title{
A life cycle approach to robust design methodology
}

\section{Vanajah Siva*, Ida Gremyr and Hendry Raharjo}

Division of Quality Sciences,

Technology Management and Economics Department, Chalmers University of Technology,

Gothenburg, Sweden

Email: vanajah.siva@chalmers.se

Email: ida.gremyr@chalmers.se

Email: hendry@chalmers.se

*Corresponding author

\section{Bolennarth Svensson}

\author{
Engineering/R\&D Department, \\ VBG Group Truck Equipment, \\ Vänersborg, Sweden \\ Email: bolennarth.svensson@vbggroup.com
}

\begin{abstract}
This paper proposes a new practice of robust design methodology (RDM); to adopt a life cycle approach to noise factor identification. Such practice expands the boundary of traditional use of robust design where noise factors are generally known, observable and experimentally controllable. By exploiting information from claim data of a medium-sized Swedish manufacturing company, several other noise factors were identified and classified into product life cycle stages; factors that are often uncontrollable, unobservable, or unknown. Exploratory data analysis, interviews, and internal documents are used in this study. The results show that by analysing the claims data, the product's failure modes can be identified and classified into various product life cycle stages. This enables identification of noise factors in each product life cycle stage. The use of a life cycle approach has two major implications. One is to expand the focus of RDM to encompass all product life cycle stages instead of being limited to a product development process. The other implication is that the practice proposed facilitates consideration of more stakeholders, in addition to one single customer by looking at consequences for society at large once the product is in use. Hence, the proposed RDM practice can be supportive of sustainable product development.
\end{abstract}

Keywords: robust design methodology; RDM; life cycle approach; noise factors; sustainable product development; back-end data.

Reference to this paper should be made as follows: Siva, V., Gremyr, I., Raharjo, H. and Svensson, B. (xxxx) 'A life cycle approach to robust design methodology', Int. J. Productivity and Quality Management, Vol. X, No. Y, pp.xxx-Xxx.

Copyright @ $20 X X$ Inderscience Enterprises Ltd. 
Biographical notes: Vanajah Siva is a Doctoral student at the Division of Quality Sciences, Department of Technology Management and Economics. She conducts her research in the extended application of robust design methodology in product development to develop practices supporting sustainable product development.

Ida Gremyr is Associate Professor/Head of Division at the Division of Quality Sciences, Department of Technology Management and Economics. Her current research areas are robust design methodology, service innovations in manufacturing industries, design for Six Sigma; relations to the area of robust design methodology and applicability in industry and healthcare.

Hendry Raharjo is an Assistant Professor at the Division of Quality Sciences, Department of Technology Management and Economics. His current research areas are quantitative research methods and applications of statistical engineering in healthcare improvement and sustainable product development.

Bolennarth Svensson is a Senior Technical Advisor within VBG Group AB. He holds a Doctorate degree within the field of quality engineering from the University of Strathclyde Glasgow. He pioneered the introduction of the concept of robust engineering in Sweden during the '80s. He has held number of significant positions within academia and industry in Sweden.

This paper is a revised and expanded version of a paper entitled 'Robust design methodology at the back-end of product development process' presented at The 14th Quality Management and Organizational Development (QMOD) Conference, San Sebastian, Spain, 29-31 August 2011.

\section{Introduction}

Genichi Taguchi, who is known as a pioneer of robust design methodology (RDM), defines quality as the losses a product imparts to the society resulting mainly from product failure during usage (Taguchi and Clausing, 1990). In other words, the focus of $\mathrm{RDM}$ is not only limited to losses to one single user, but also to the society at large. RDM has been known as a useful tool supportive of upstream quality efforts (Arvidsson and Gremyr, 2008; Hasenkamp et al., 2009), i.e., efforts during product development. This is well in line with the thoughts underlying sustainable product development (SPD) where the emphasis of environmental impacts have shifted from end-of-life strategies such as recycle and waste management to upstream efforts of integrating sustainability considerations in product design (Johansson, 2002).

Practices of RDM in early phases of product development have come into focus lately (Hasenkamp et al., 2009). However, there are noise factors, e.g., related to use phase that are not easily identified through front-end efforts. Not much emphasis has been given to how data derived from the back-end of the product development process can be used to support front-end robustness efforts, e.g., by supporting identification of noise factors occurring during product use. Back-end data is defined here as production data as well as claims data from customers during the product use stage. In organisations, there is often no shortage in availability of such data. Rather, scarce attention is given to the role of back-end data in providing feedback to product and process quality issues (Saccani et al., 2006), and there is a lack of use of the data to drive improvements (Fundin and Bergman, 
2003). Customer claims data is a source of information from the product use stage, creating opportunity to understand the conditions in which products are used. These conditions vary in its effect on products, from optimal for product usage to conditions causing failures of products. The conditions related to or causing failures are, at times, referred to as noise factors (Phadke, 1989).

In efforts to achieve SPD, a life cycle approach is commonly adopted (Klöpffer, 2003). In this adoption, a product is categorised based on various life cycle stages, namely raw material, manufacturing, distribution, use and end-of-life. Analysis of customer claims data allows retrieval of information on failures modes. These failure modes and their causes can be related to one or more stages of a product life cycle. Hence, the related noise factors could also be linked to one or more stages of life cycle.

The purpose of this paper is to propose a new practice of RDM by adopting a life cycle approach to noise factor identification. Such practice expands the boundary of traditional use of RDM where noise factors are generally known, observable and experimentally controllable (Johansson et al., 2006). By exploiting information from back-end data (i.e., claim data) of a medium-sized Swedish manufacturing company, we identified several other noise factors which are often uncontrollable, unobservable, or unknown and classified them into product life cycle stages. Exploratory data analysis, interviews, and internal document analysis were used in this study. The practice suggested addresses two research niches; lack of practices of RDM to use back-end data as a means to support its continuous application throughout product life cycle, and limited elaborations on links between RDM principles and sustainable product development (Gremyr et al., 2014).

This paper contributes to RDM by taking a product life cycle approach when identifying noise factors; pointing to noise factors influencing various stages which can provide opportunities to continuously work on achieving robustness. More generally, identification of noise factors throughout product life cycle stages may contribute to increased knowledge on what affects product performance over its entire life cycle.

This paper is structured as follows. Section 2 provides the theoretical background. Section 3 describes the research methodology. The results of the claims data analysis are presented in Section 4, followed by discussions and conclusion in Section 5.

\section{Theoretical background}

The theoretical background addresses three main themes: RDM, back-end opportunities, and product life-cycle approach.

\subsection{Robust design methodology}

According to Taguchi, the definition of robustness is "the state where ... the product ... performance is minimally sensitive to factors causing variability ... and aging” [Taguchi et al., (2000), p.4]. Based on this definition, robustness is achieved when variations are taken into consideration during product design stage. Sources of variation that can be controlled are referred to as control factors; whereas those that cannot be controlled or are expensive to control are referred to as noise factors (NFs). A P-diagram is often used to conceptually analyse NFs and their influence on a product or process, as shown in Figure 1 (Phadke, 1989). 
Figure 1 P-diagram

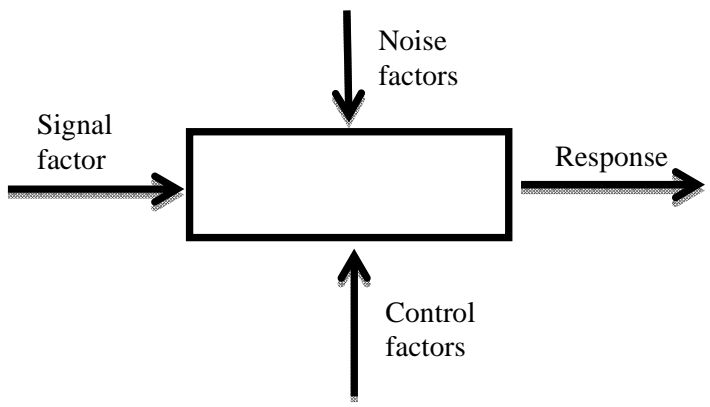

NFs can be classified based on their manifestation environment and degree of knowledge (Johansson et al., 2006). According to their manifestation environment, NFs can be classified into those in-production (e.g., manufacturing imperfections that cause unit-to-unit variation) and those in-use (e.g., external conditions such as user-to-user variation, and internal conditions such as product wear and degradation during usage). According to the degree of knowledge, NFs can be divided into sub-categories of known and unknown, where known factors are divided into observable and unobservable. The observable NFs are then divided further into experimentally controllable and uncontrollable.

Experimental tools, such as design of experiment, are applicable for assessing the NFs that are known, observable, and experimentally controllable. This leaves out various other NFs which are unknown, unobservable, and uncontrollable. Furthermore, despite the fact that noise factor identification is a critical activity in RDM (Taguchi and Clausing, 1990), a lot of the efforts to date have been focused on improving existing statistical techniques in creating insensitivity to NFs (Tsui, 1992) with rather little emphasis on practices supporting the actual identification of NFs.

In general, RDM is described as a front-end approach to reduce performance variation in products and processes (Shoemaker et al., 1991; Andersson, 1996; Goh, 2002; Park et al., 2006; Amuthakkannan, 2012; Shahin, 2012). In a conceptual discussion on RDM, a need has been raised to explore applications of RDM based on its underlying principles (Arvidsson and Gremyr, 2008) and to increase focus on practices of RDM as opposed to a main focus on tools (Hasenkamp et al., 2009). In fact, a clear gap has been identified in the lack of practices related to RDM application. More specifically, there is a lack of practices supporting continuous applicability of RDM throughout product development stages (Hasenkamp et al., 2009). This creates a need for RDM practices to focus on, not only the front-end of product development, that is the design stage, but also the back-end (Siva, 2012).

\subsection{Back-end opportunities}

Product development activities are conducted in a continuum which could be divided into front-end and back-end of development (Cooper and Kleinschmidt, 1986). Both ends are critical in establishing successful development efforts, e.g., after-sale stages is a source of knowledge that can be tapped into (Poolton and Barclay, 1998). One source of knowledge from the back-end is customer claims data related to product failures in the 
field. A number of opportunities for improvements could be found in analyses of field data such as customer claims (Fundin and Bergman, 2003; Fundin and Elg, 2006, 2010). A main challenge faced by managers concerning claims data is not in the availability of data, but rather in answering the question of what could be done with the data, and how (Fundin and Bergman, 2003). This is related to the lack of a systematic approach for customer claims handling in many organisations (Zairi, 2000).

Information regarding failures of products, conditions of use during failures, and failures of specific components are valuable information in the improvement of product reliability and quality (Meeker and Escobar, 2004). In the design stage, designers are able to anticipate certain failures and make relevant design considerations to counter the failures. This is not the case for all failures. Unexpected failures occur in the field, e.g., due to variations in conditions of use, mishandling, or wrong use of products. The information concerning such incidents may be captured in the claims data, which is beneficial in understanding the reliability of products. A need of a reliability-oriented feedback system is required in order to improve design work (Magniez et al., 2009). Feedback from claims data should also be seen as a critical information channel, where flow of information from customers to various functions involved in product development can take place (Molenaar et al., 2002).

\subsection{Product life cycle approach}

SPD has developed from discussions of consumption imbalance of natural resources in the world (Van Weenen, 1995) to integration of sustainability aspects in existing product development tools based on product life cycle approach (Luttropp and Lagerstedt, 2006). Integration of sustainability requirements in existing tools and methodologies is one way to contribute to SPD efforts (Masui et al., 2003). This integration is argued a necessary step in all stages of a product life cycle in order to support SPD (Kaebernick et al., 2003). An example of a life-cycle-based methodology is life cycle assessment (LCA); widely recognised as a way to assess environmental impacts of products and processes (Kaebernick et al., 2003; Vinodh and Rathod, 2010).

SPD, based on the cradle-to-grave approach, was seen as an initiative of transitioning the focus from product end-of-life sustainability impacts, such as recycle and reuse, to reduced impacts across the life cycle of a product (Rydberg, 1995; Hanssen, 1999; Ljungberg, 2007; Gehin et al., 2008). A product life cycle refers to the stages that a product 'followed from its 'cradle' where raw materials are extracted from natural resources through production and use to its 'grave”' [Baumann and Tillman, (2004), p.19]. The product life cycle approach in reducing environmental impacts is often discussed as a beneficial approach towards SPD (Kaebernick et al., 2003; Bhamra, 2004).

The systems view in a life cycle approach is argued necessary to maintain a balance by focusing on all stages of product life cycle in addressing sustainability considerations (Klöpffer, 2003). Klöpffer (2003, p.134) stated that

\footnotetext{
"any environmental, economic, or social assessment method for products has to take into account the full life cycle from raw material extraction, production to use and recycling or waste disposal. In other words, a systems approach has to be taken. Only in this way, trade-offs can be recognised and avoided. Life cycle thinking is the prerequisite of any sound sustainability assessment.”
} 
Common stages of a product life cycle comprise of raw material, manufacturing, distribution, use, and end-of-life (Choi et al., 2008). A number of strategies have been identified by Choi et al. (2008) in addressing sustainability considerations in each of these stages, as shown in Table 1.

Table 1 Life cycle stages and strategies

\begin{tabular}{lc}
\hline Life cycle stages & Strategies \\
\hline Raw material (RM) & Reduction of material use \\
& Use of recycle and recyclable material \\
Avoid toxic or hazardous substances & Avoid waste of material \\
Manufacturing (Mfg) & Clean production \\
Distribution (Distr) & Minimised variety of material \\
& Reduced weight of product \\
Product use & Reduced weight of packaging \\
& Re-use and recyclable packaging \\
& Avoidance of waste \\
End-of-life (EoL) & Product durability \\
& Product efficiency \\
& Re-use and recycle \\
& Remanufacturing \\
\end{tabular}

Source: Choi et al. (2008)

\section{Methodology}

This section is divided into two main sections. The first comprises of methods applied in the process of collecting interview data; followed by a second section on collection and analysis of the claims data.

\subsection{Interview data}

One data collection method was interviews, aiming to understand the functions of the claims database within the organisation. The interviews were of a semi-structured type, i.e., the overall questions were specified to cover the intended themes whereas detailed questions within the themes can vary between interviews. The pre-defined overall questions can be found in Appendix. The questions were formulated to gain knowledge of the claims handling process, in terms of input data, data entry process, frequency of data entry, and the way the claims data was processed and utilised in terms of claims authorisation, report generation, claims data update and maintenance of database.

The two main interviewees were directly involved in the claims handling process. They were responsible for claims data entry and handling of claims for two different customer segments. The interviews took between three to four hours each. The 
interviewees were continuously consulted by the authors, and asked follow-up questions for further clarifications as and when necessary.

The quality manager at the organisation was added as another interviewee to further understand the current challenges in using the claims data for improvement purposes within the organisation. The interview covered the same areas as described above, see Appendix. This interview lasted two hours. Several meetings were held with the main contact person at the organisation, who was an engineer responsible for product and process improvement initiatives within the organisation. These meetings usually lasted between two to three hours each session, in a total six full day visits. Interviews and meetings were conducted in English. All interviews were recorded and transcribed.

The interviews provided insights into the claims handling process, whereas the data analysis elaborated on in the following subsection was used to explore potentials of the claim data in supporting RDM. This analysis will further be the basis for developing the proposed RDM practice.

\subsection{Claims data}

The claims data was extracted from the Microsoft Access database and imported to statistical software (JMP), for quantitative analysis. The dataset analysed in this study contained claims data of five years, from 2006 until end of 2010. It includes claims within and without the guarantee period; allowing for analysis of data from a broad range of life-cycle stages. The database was explored by studying the lists of failure codes, customers, and various claims reports stored in the database, including reports on claims generated for periodic top management review.

The analysis of a large dataset was done in an exploratory manner, where there is a need to understand what is going on by looking at the data. In such situation, EDA has been advocated to be a fitting analysis method (Tukey, 1962). The goal of EDA is to discover patterns in data through 'listening' to the data in as many ways as possible until a plausible 'story' of the data is apparent (Behrens, 1997). In the process of EDA, a number of steps can be discerned, namely display of data, identification of salient features, and interpretation of those salient features (De Mast and Trip, 2007). Salient features refers to features that stand out from what was expected a priori (De Mast and Kemper, 2009). In this step of the process, a neutral reference distribution is identified. A reference distribution reflects an existing knowledge about the phenomena under study but is neutral with respect to other features. The third step of the process is essentially a non-statistical one, which is to theorise and speculate on the causes of patterns identified from earlier step. Interpretations of patterns or causes identified require expert knowledge of the subject, as stated in the fourth principle of EDA (De Mast and Kemper, 2009).

The EDA steps were applied in the analysis in JMP, where data was displayed through distribution, in the graphical form of histograms in order to capture patterns, and identify salient features. In the use of EDA, ideas are generated through confrontation between empirical data and subject matter knowledge (De Mast and Kemper, 2009). The histograms derived from the data analysis were analysed based on data collected through interviews and information gathered from meetings.

As a final step in the data analysis, failures are inductively related to possible noise factors based on remarks in the claims database on the situation in which the failure occurred. The failures, and related noise factors, are classified according to the life cycle 
stages. As part of the validation, the results from this step were discussed with the main contact person at the organisation, who was a subject matter expert.

The proposed practice of analysing claims data by the EDA method in order to identify noise factors specific to certain life cycle stages is summarised in Figure 2.

Figure 2 The practice summarised in steps: 1) EDA for the back-end data, 2) failures classified based on life cycle stages, 3) noise factor identification, and 4) feedback to product development

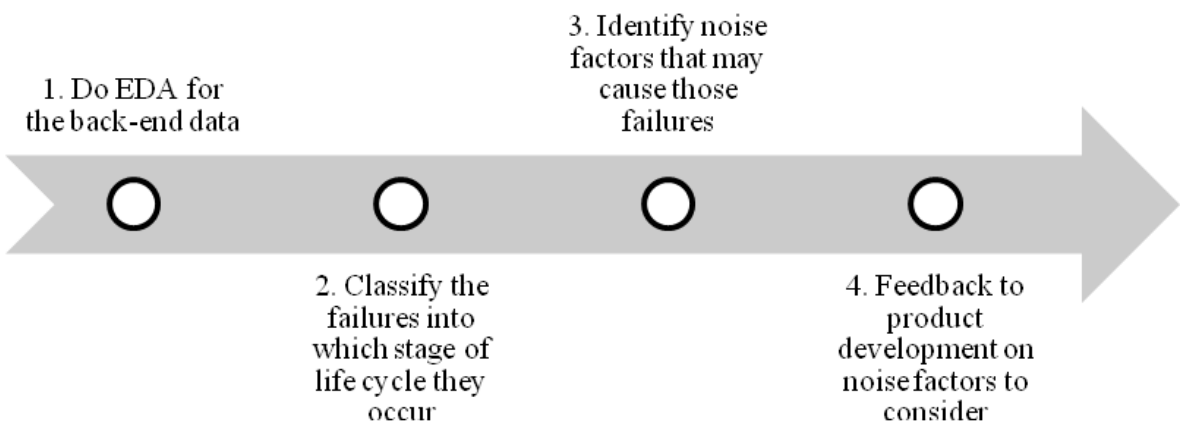

\section{Results}

Display of claims data in histograms enabled identification of salient features. The first attempt of visualising the data led to several findings including the identification of most problematic areas of claims categorised by customer, failures modes, and parts. For the sake of simplicity further analysis will focus on the number of claims by parts. The analysis will illustrate how the claim data analysis may lead to the identification of noise factors throughout product life cycle.

Figure 3 shows a truncated histogram of number of claims of a total of 109 parts from 2006 to 2010. Note that the parts' names are not shown in the histogram due to confidentiality reason. For ease of reference, a set of codes such as 'P1', 'P2',...,'P5' is used to refer to the highest number of claims, second highest, and so forth (see Table 2).

Figure 3 Truncated histogram of number of claims by parts from year 2006 to 2010 (see online version for colours)

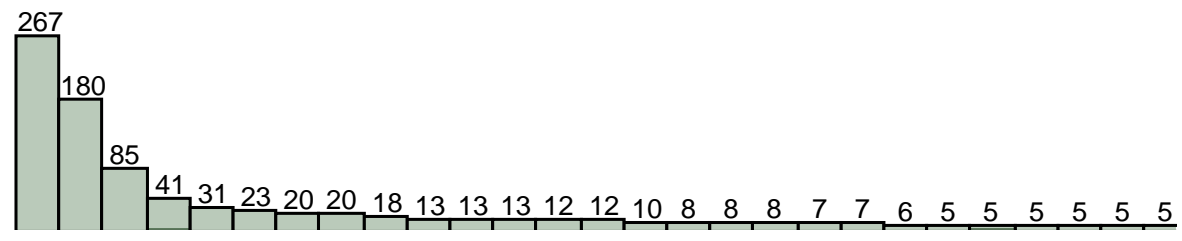


Table 2 Percentage of claims by parts adjusted by sales data

\begin{tabular}{lccc}
\hline Part & Number of claims & Number of sales & \% of claims \\
\hline P1 & 267 & 25,941 & 1.03 \\
P2 & 180 & 19,908 & 0.90 \\
P3 & 85 & 5,880 & 1.45 \\
P4 & 41 & 1,011 & $\mathbf{4 . 0 6}$ \\
P5 & 31 & 13,971 & 0.22 \\
\hline
\end{tabular}

It is not difficult to see that the number of claims by parts may depend on how many units were sold for a particular part. In other words, one may not conclude directly that the first part (P1), which has a total of 267 claims, is the most problematic one. After some discussions with the subject matter expert, it was found out that the number of claims by parts should be adjusted by the sales figures. In this case, the sales figures serve as the neutral reference distribution in the sense that the number of units for each part is more or less the same. However, as can be seen in Table 3, the number of units for each part differs a lot from each other. This led to the finding that ' $\mathrm{P} 4$ ' is the most problematic part.

Having identified 'P4' as the most problematic part, a further analysis of the claims pointed to a number of influential noise factors. As described above, noise factors, according to their manifestation environment, are generally classified into those 'inproduction' and those 'in-use'. Knowledge about as many noise factors as possible is critical to support continuous applicability of RDM throughout product development. For claims data analysis, the most obvious category of noise factors underlying the claims is 'in use'; as it concern claims from the field. However, the root cause of the problem underlying the claims might well have arisen in other life cycle stages than use stage. Further analysis of 'P4' was structured based on the life cycle stages (raw material, manufacturing, distribution, use and end-of-life). Hence, the analysis supported identification of noise factors throughout the life cycle stages and consequently can be supportive of continuous applicability of RDM. Table 3 displays parts of this analysis as an illustration; containing failure modes causing claims of ' $\mathrm{P} 4$ '.

Table 3 reveals that failures modes can be related to various life cycle stages, and hence various noise factors can therefore be related to these failures modes. Examples related to the use phase are various conditions of use such as long haulage, distribution of merchandise, logging, off-road and construction sites usage. Moreover there are variations in between users although using the product for the same purpose; this is often related to driver style, maintenance and care of the product. All of these variations being related to the use phase, Table 3 also points to the need to focus at the other life cycle stages in analysing some failures. An example is the manufacturing stage where noise factors related to manufacturing conditions come into focus, exemplified by variation in operator skills. This type of analysis leading to identification of a set of noise factors can form a basis for action plans to address the high number of claims of 'P4' by attempting to create insensitivity to the noise factors. 
Table 3 Illustration of failure modes causing claims of P4 classified into life cycle stages

\begin{tabular}{|c|c|c|c|c|c|c|}
\hline Failure mode & $R M$ & $M f g$ & Distr & Use & $E o L$ & Possible NFs \\
\hline \multirow[t]{2}{*}{ Abuse, overloading } & & & & & & Variation in loads \\
\hline & & & & & & Improper maintenance \\
\hline Spring retainer loose & & & & & & Improper maintenance \\
\hline Normal wear & & & & & & Wear and degradation \\
\hline Faulty process & & & & & & Variation in operator knowledge \\
\hline \multirow[t]{2}{*}{ Faulty tolerance } & & & & & & Variation in operator knowledge \\
\hline & & & & & & Poor quality in specification \\
\hline Wrong delivery number/part & & & & & & User training \\
\hline Lack of maintenance & & & & & & Poor vehicle owners procedure \\
\hline Wrong installation & & & & & & Variation in operator skill \\
\hline Worn lifting arm & & & & & & Variation in loads \\
\hline
\end{tabular}

\section{Discussions and conclusions}

Viewing RDM as a way to minimise quality loss imparted to society (Taguchi and Clausing, 1990) can contribute to sustainability, but raises a need to study not only what happens when the product is produced and used, but also what happens in other life cycle stages, for example, in distribution or end-of-life stage. This is in line with notions on the need to extend applications of RDM to exploit opportunities to create robustness throughout a product development process (Clausing, 1994). This paper adds to this by applying a product life-cycle approach (Klöpffer, 2003), and not limiting the work on robustness to addressing opportunities in a product development process. Hence, continuous applicability, one of the principles of RDM (Arvidsson and Gremyr, 2008) is re-defined to account for all product life cycle stages instead of a product development process.

Specifically, the practices proposed in this paper are related to the use of back-end data. Not only does it support a view on RDM as concerning various stages of a product's life, it has also been identified as an untapped source for improvements (Poolton and Barclay, 1998; Fundin and Elg, 2006). This study contributes by linking back-end data to $\mathrm{RDM}$, as a critical source to information of noise factors across product life cycle stages. Moreover, the claim analysis can be supportive of the continuous applicability principle of RDM in the product development process of the organisation. The claims analysis constitutes one way of getting customer feedback concretely linked to improvement activities, contributing to improved quality in subsequent product development projects.

To further investigate the relationships between various departments of the organisation with respect to using the results from claims data analysis is an area of future research. More test cases in other settings or companies will certainly provide better evidence for justifying the advantage of the proposed practice in addressing quality problems and possible noise factors.

To sum up, this paper has proposed a new practice of RDM by adopting a life cycle approach to noise factor identification. The use of life cycle approach has two major implications. First, it expands the focus of RDM to encompass all product life cycle 
stages instead of being limited to a product development process. This helps identify noise factors throughout product life cycle stages, of which some were uncontrollable, unobservable, or unknown, in addition to the traditional noise factors which are generally known, observable and experimentally controllable (Johansson et al., 2006). Second, the suggested approach facilitates consideration of more stakeholders in addition to one single customer, as it focuses on the whole life-cycle and therefore can also capture long-term effects, e.g., on the environment. Hence, such attempt, we believe, can support RDM practice towards sustainable product development.

\section{Acknowledgements}

This work has been carried out within the Sustainable Production Initiative and the Production Area of Advance at Chalmers. The support is gratefully acknowledged.

\section{References}

Amuthakkannan, R. (2012) 'Parameters design and performance analysis of a software-based mechatronics system using Taguchi robust design-a case study’, International Journal of Productivity and Quality Management, Vol. 10, No. 1, pp.1-24.

Andersson, P. (1996) 'A semi-analytic approach to robust design in the conceptual design phase', Research in Engineering Design, Vol. 8, No. 4, pp.229-239.

Arvidsson, M. and Gremyr, I. (2008) 'Principles of robust design methodology', Quality and Reliability Engineering International, Vol. 24, No. 1, pp.23-35.

Baumann, H. and Tillman, A.M. (2004) The Hitch Hiker's Guide to LCA - An Orientation in Life Cycle Assessment Methodology and Application, Studentlitteratur, USA.

Behrens, J.T. (1997) 'Principles and procedures of exploratory data analysis', Psychological Methods, Vol. 2, No. 2, pp.131-160.

Bhamra, T. (2004) 'Ecodesign: the search for new strategies in product development', Proceedings of the Institution of Mechanical Engineers, Part B: Journal of Engineering Manufacture, Vol. 218, No. 5, pp.557-569.

Choi, J., Nies, L. and Ramani, K. (2008) 'A framework for the integration of environmental and business aspects toward sustainable product development', Journal of Engineering Design, Vol. 19, No. 5, pp.431-446.

Clausing, D. (1994) Total Quality Development: A Step-By-Step Guide to World Class Concurrent Engineering, American Society of Mechanical Engineers, Cambridge, Massachusetts.

Cooper, R.G. and Kleinschmidt, E.J. (1986) 'An investigation into the new product process: steps, deficiencies, and impact', Journal of Product Innovation Management, Vol. 3, No. 2, pp.71-85.

De Mast, J. and Kemper, B.P.H. (2009) 'Principles of exploratory data analysis in problem solving: what can we learn from a well-known case?’, Quality Engineering, Vol. 21, No. 4, pp.366-375.

De Mast, J. and Trip, A. (2007) 'Exploratory data analysis in quality improvement projects, Journal of Quality Technology, Vol. 39, No. 4, p.301.

Fundin, A. and Elg, M. (2006) 'Exploring routes of dissatisfaction feedback: a multiple case study within a machine industry segment', International Journal of Quality \& Reliability Management, Vol. 23, No. 8, pp.986-1001.

Fundin, A. and Elg, M. (2010) 'Continuous learning using dissatisfaction feedback in new product development contexts', International Journal of Quality \& Reliability Management, Vol. 27, No. 8, pp.860-877. 
Fundin, A.P. and Bergman, B.L.S. (2003) 'Exploring the customer feedback process', Measuring Business Excellence, Vol. 7, No. 2, pp.55-65.

Gehin, A., Zwolinski, P. and Brissaud, D. (2008) 'A tool to implement sustainable end-of-life strategies in the product development phase', Journal of Cleaner Production, Vol. 16, No. 5, pp.566-576.

Goh, T.N. (2002) 'The role of statistical design of experiments in Six Sigma: perspectives of a practitioner’, Quality Engineering, Vol. 14, No. 4, pp.659-671.

Gremyr, I., Siva, V., Raharjo, H. and Goh, T.N. (2014) 'Adapting the robust design methodology to support sustainable product development', Journal of Cleaner Production, in press, DOI: 10.1016/j.jclepro.2014.05.018.

Hanssen, O. (1999) 'Sustainable product systems - experiences based on case projects in sustainable product development', Journal of Cleaner Production, Vol. 7, No. 1, pp.27-41.

Hasenkamp, T., Arvidsson, M. and Gremyr, I. (2009) 'A review of practices for robust design methodology’, Journal of Engineering Design, Vol. 20, No. 6, pp.645-657.

Johansson, G. (2002) 'Success factors for integration of Ecodesign in product development: a review of state of the art', Environmental Management and Health, Vol. 13, No. 1, pp.98-107.

Johansson, P., Chakhunashvili, A., Barone, S. and Bergman, B. (2006) 'Variation mode and effect analysis: a practical tool for quality improvement', Quality and Reliability Engineering International, Vol. 22, No. 8, pp.865-876.

Kaebernick, H., Kara, S. and Sun, M. (2003) 'Sustainable product development and manufacturing by considering environmental requirements', Robotics and Computer-Integrated Manufacturing, Vol. 19, No. 6, pp.461-468.

Klöpffer, W. (2003) 'Life-cycle based methods for sustainable product development', The International Journal of Life Cycle Assessment, Vol. 8, No. 3, pp.157-159.

Ljungberg, L.Y. (2007) 'Materials selection and design for development of sustainable products', Materials \& Design, Vol. 28, No. 2, pp.466-479.

Luttropp, C. and Lagerstedt, J. (2006) 'EcoDesign and the ten golden rules: generic advice for merging environmental aspects into product development', Journal of Cleaner Production, Vol. 14, Nos. 15-16, pp.1396-1408.

Magniez, C., Brombacher, A.C. and Schouten, J. (2009) 'The use of reliability oriented field feedback information for product design improvement: a case study', Quality and Reliability Engineering International, Vol. 25, No. 3, pp.355-364.

Masui, K., Sakao, T., Kobayashi, M. and Inaba, A. (2003) 'Applying quality function deployment to environmentally conscious design, International Journal of Quality \& Reliability Management, Vol. 20, No. 1, pp.90-106.

Meeker, W.Q. and Escobar, L.A. (2004) 'Reliability: the other dimension of quality', Quality Technology \& Quantitative Management, Vol. 1, No. 1, pp.1-25.

Molenaar, P., Huijben, A., Bouwhuis, D. and Brombacher, A. (2002) 'Why do quality and reliability feedback loops not always work in practice: a case study', Reliability Engineering \& System Safety, Vol. 75, No. 3, pp.295-302.

Park, G-J., Lee, T-H., Lee, K.H. and Hwang, K-H. (2006) 'Robust design: an overview', AIAA Journal, Vol. 44, No. 1, pp.181-191.

Phadke, M.S. (1989) Quality Engineering Using Robust Design, PTR Prentice-Hall Inc., New Jersey, USA.

Poolton, J. and Barclay, I. (1998) 'New product development from past research to future applications', Industrial Marketing Management, Vol. 27, No. 3, pp.197-212.

Rydberg, T. (1995) 'Cleaner products in the Nordic countries based on the life cycle assessment approach: the Swedish product ecology project and the Nordic project for sustainable product development', Journal of Cleaner Production, Vol. 3, No. 1, pp.101-105. 
Saccani, N., Songini, L. and Gaiardelli, P. (2006) 'The role and performance measurement of after-sales in the durable consumer goods industries: an empirical study', International Journal of Productivity and Performance Management, Vol. 55, Nos. 3/4, pp.259-283.

Shahin, A., Janatyan, N. and Nasirzaheh, N. (2012) 'Service quality robust design - with a case study in airport services', International Journal of Productivity and Quality Management, Vol. 9, No. 3, pp.404-421.

Shoemaker, A.C., Tsui, K.L. and Wu, C.F.J. (1991) 'Economical experimentation methods for robust design', Technometrics, Vol. 33, No. 4, pp.415-427.

Siva, V. (2012) 'Improvement in product development: use of back-end data to support upstream efforts of robust design methodology, Quality Innovation Prosperity, Vol. 16, No. 2, pp.84-102.

Taguchi, G. and Clausing, D. (1990) 'Robust quality’, Harvard Business Review, Vol. 68, No. 1, pp.65-75.

Taguchi, G., Chowdhury, S. and Taguchi, S. (2000) Robust Engineering: Learn How to Boost Quality While Reducing Costs \& Time to Market, McGraw-Hill Education, USA.

Tsui, K.L. (1992) 'An overview of Taguchi method and newly developed statistical methods for robust design', IIE Transactions, Vol. 24, No. 5, pp.44-57.

Tukey, J.W. (1962) 'The future of data analysis', The Annals of Mathematical Statistics, Vol. 33, No. 1 , pp.1-67.

Van Weenen, J. (1995) 'Towards sustainable product development', Journal of Cleaner Production, Vol. 3, Nos. 1-2, pp.95-100.

Vinodh, S. and Rathod, G. (2010) 'Integration of ECQFD and LCA for sustainable product design', Journal of Cleaner Production, Vol. 18, No. 8, pp.833-842.

Zairi, M. (2000) 'Managing customer dissatisfaction through effective complaints management systems', The TQM Magazine, Vol. 12, No. 5, pp.331-337.

\section{Appendix}

\section{List of main questions used during semi-structured interview}

Main questions to two interviewees involved in claim handling process

1 How often is claims data entered into the system?

2 What actions are taken during claims handling?

3 What types of reports are generated from the claims database?

Main questions to quality manager

1 How does your department handle claims?

2 How do you categorise the failures identified in claims reports?

3 What are the actions taken to address a quality defect identified in the claims? 